Portland State University

PDXScholar

\title{
Inertial and Liquefaction-Induced Kinematic Demands on a Pile-Supported Wharf: Physical Modeling
}

Milad Souri

Portland State University

Arash Khosravifar

Portland State University, karash@pdx.edu

Stephen E. Dickenson

New Albion Geotechnical

Scott Schlechter

GRI

Nason McCullough

FH $2 \mathrm{M} M$ this and additional works at: https://pdxscholar.library.pdx.edu/cengin_fac

Part of the Civil Engineering Commons, Environmental Engineering Commons, and the Structural Engineering Commons

Let us know how access to this document benefits you.

\section{Citation Details}

Souri, Milad; Khosravifar, Arash; Dickenson, Stephen E.; Schlechter, Scott; and McCullough, Nason, "Inertial and Liquefaction-Induced Kinematic Demands on a Pile-Supported Wharf: Physical Modeling" (2018). Civil and Environmental Engineering Faculty Publications and Presentations. 449.

https://pdxscholar.library.pdx.edu/cengin_fac/449

This Post-Print is brought to you for free and open access. It has been accepted for inclusion in Civil and Environmental Engineering Faculty Publications and Presentations by an authorized administrator of PDXScholar. Please contact us if we can make this document more accessible: pdxscholar@pdx.edu. 


\title{
Inertial and Liquefaction-Induced Kinematic Demands on a Pile-Supported Wharf: Physical Modeling
}

\author{
Milad Souri' ${ }^{1}$ Arash Khosravifar, Ph.D., P.E. M.ASCE ${ }^{2}$, Stephen E. Dickenson, Ph.D., P.E., \\ D. PE ${ }^{3}$, Scott Schlechter, P.E., G.E. ${ }^{4}$, Nason McCullough, Ph.D., P.E., G.E. ${ }^{5}$
}

${ }^{1}$ Department of Civil and Environmental Engineering, Portland State University, Portland, OR 97201; e-mail: msouri@pdx.edu

${ }^{2}$ Department of Civil and Environmental Engineering, Portland State University, Portland, OR 97201; e-mail: karash@pdx.edu

${ }^{3}$ New Albion Geotechnical, Inc., Reno, NV 89509; e-mail: sed@newalbiongeotechnical.com

${ }^{4}$ GRI, Beaverton, OR 97008; e-mail: SSchlechter@gri.com

${ }^{5} \mathrm{CH} 2 \mathrm{M}$, Corvallis, OR 97330; e-mail: Nason.McCullough@

\begin{abstract}
Results of a centrifuge test on a pile-supported wharf were used to investigate the time-, depth-, and row-dependent nature of kinematic and inertial loading on wharf piles in sloping rockfill. P-y models were calibrated against recorded bending moments in different piles and different depths. It was found that full kinematic demands and full superstructure inertia should be combined to estimate bending moments at pile head and shallow depths (less than 10 diameters below the ground surface). On the contrary, it was found that applying full kinematic demands alone was adequate to estimate pile bending moments at large depths (greater than 10 diameters deep).
\end{abstract}

\section{INTRODUCTION}

Pile foundations in sloping soils should be designed to sustain loading due to both permanent ground deformation (kinematic) and inertia of the structure during shaking. Current design recommendations vary significantly on how to combine inertia and kinematic loads. For example, AASHTO (2014) recommends designing piles for simultaneous effects of inertia and ground deformation (e.g., lateral spreading) only for large magnitude earthquakes (M>8). Caltrans (2012) and ODOT (Ashford et al. 2012) recommend combining 100\% lateral spreading with 50\% inertia. Washington DOT recommend combining $100 \%$ lateral spreading with $25 \%$ inertia (WSDOT 2015). The Port of Long Beach Wharf Design Criteria (POLB 2015) suggests that for their common wharf configurations and soils the locations of maximum bending moments from inertia and lateral spreading are spaced far enough apart that the two loads do not need to be superimposed. It also assumes that the maximum bending moments from the two loads tend to occur at different times; therefore, it recommends that the two loads be treated as uncoupled for typical marginal container wharves at the Port of Long Beach. For other types of wharves, both POLB (2015) and ASCE COPRI 61-14 (2014) recommend evaluating this assumption on a 
project-specific basis. Tokimatsu et al. (2005) recommended in-phase and out-of-phase combination of inertia and lateral spreading based on the natural periods of soil and structure.

The objective of this study is to identify inertial and kinematic loads on piles (i.e., bending moments) at different depths. For piles in nonliquefied conditions (minimal kinematic demands) the contribution of inertial forces from superstructure is known to attenuate within approximately 8 to 10-diameter depth below the ground surface (depending on the relative stiffness of soil and pile). Data from a large-scale centrifuge test on a pile-supported wharf and practice-oriented p-y models were used to investigate whether the same attenuation occurs in liquefied conditions where kinematic demands are large. The piles in this centrifuge test were subjected to liquefactioninduced lateral spreading combined with wharf deck inertia. P-y models where calibrated to measured response in the centrifuge test, then applied to provide insights on how kinematic and inertial demands should be combined in design of similar pile-supported wharf configurations. It will be shown that large bending moments at depth (above and below the liquefiable layer) are primarily induced by kinematic demands and can be estimated by applying kinematic demands only. On the contrary, large bending moments at shallow depths (pile head or at ground surface) are induced by the combination of kinematics and inertia; therefore, both demands should be combined to more accurately estimate pile bending moments at shallow depths.

\section{CENTRIFUGE TEST}

A series of five centrifuge tests was conducted by Dickenson, McCullough, Schlechter and coworkers at the UC Davis Center for Geotechnical Modeling (McCullough et al. 2001). These tests were conducted on pile-supported wharfs and foundation soils that included rockfill, saturated sand deposits, and soft marine clay. This paper focuses on the results of one of these centrifuge tests (NJM01; McCullough et al. 2000). The cross section of the physical model is shown in Figure 1. The dimensions discussed in this paper are in prototype scale, unless noted otherwise.

The centrifuge acceleration was $40.1 \mathrm{~g}$. The soil layers include rockfill dikes that deformed due to liquefaction of the underlying loose sand. Loose to dense Nevada sand was used with relative densities $\left(D_{R}\right)$ ranging from $39 \%$ to $82 \%$. The piles were aluminum tubes with prototype diameter of $0.64 \mathrm{~m}$. Table 1 lists the pile and deck properties used in this test. The model was constructed in a flexible shear beam container, which was designed to have a shear modulus compatible to that of liquefied soils. The pore fluid was a mixture of methylcellulose, which has a higher viscosity than that of water. This was done to reconcile different time scales for the dynamic and diffusion equations. The test was subjected to multiple, scaled input motions. The results presented in this paper are for the 1989 Loma Prieta earthquake motions recorded at the Port of Oakland Outer Harbor Wharf station scaled to a PGA of $0.15 \mathrm{~g}$. The centrifuge model used in this study simulates a typical pile-supported wharf embedded in rock dikes over liquefiable layers. This cross section represents the common layout of major port facilities in California. The findings from this test can be applied to other port facilities with similar subsurface conditions and structural properties. Data from the other four centrifuge tests are being analyzed to evaluate the time-, depth, and row-dependent nature of kinematic and inertial loading on wharf piles in sloping rockfill. 
Table 1. Pile and Deck Properties in Centrifuge Test NJM01 ${ }^{1}$

\begin{tabular}{|l|l|l|}
\hline & Values in Prototype Scale & Values in Model Scale \\
\hline Pile & Pile group (3-by-7) & Pile group (3-by-7) \\
& Pile $\mathrm{b}=0.64 \mathrm{~m}, \mathrm{t}=0.036 \mathrm{~m}, \mathrm{~L}=27.23 \mathrm{~m}$ & Pile $\mathrm{b}=15.9 \mathrm{~mm}, \mathrm{t}=0.899 \mathrm{~mm}$, \\
& $\mathrm{EI}=2.134 \mathrm{e} 5 \mathrm{kPa}-\mathrm{m}^{4}$ & $\mathrm{~L}=679 \mathrm{~mm}, \mathrm{EI}=82.536 \mathrm{~Pa}-\mathrm{m}^{4}$ \\
\hline Wharf Deck & Dimensions: $33.68 \mathrm{~m} \mathrm{x} 15.24 \mathrm{~m} \times 0.25 \mathrm{~m}$ & Dimensions: $839.9 \mathrm{~mm} \times 380.1 \mathrm{~mm} \mathrm{x}$ \\
& Mass $=350445 \mathrm{~kg}$ & $6.2 \mathrm{~mm}$, Mass $=5.43 \mathrm{~kg}$ \\
\hline
\end{tabular}

1. Centrifuge Scale Factor $=40.1$

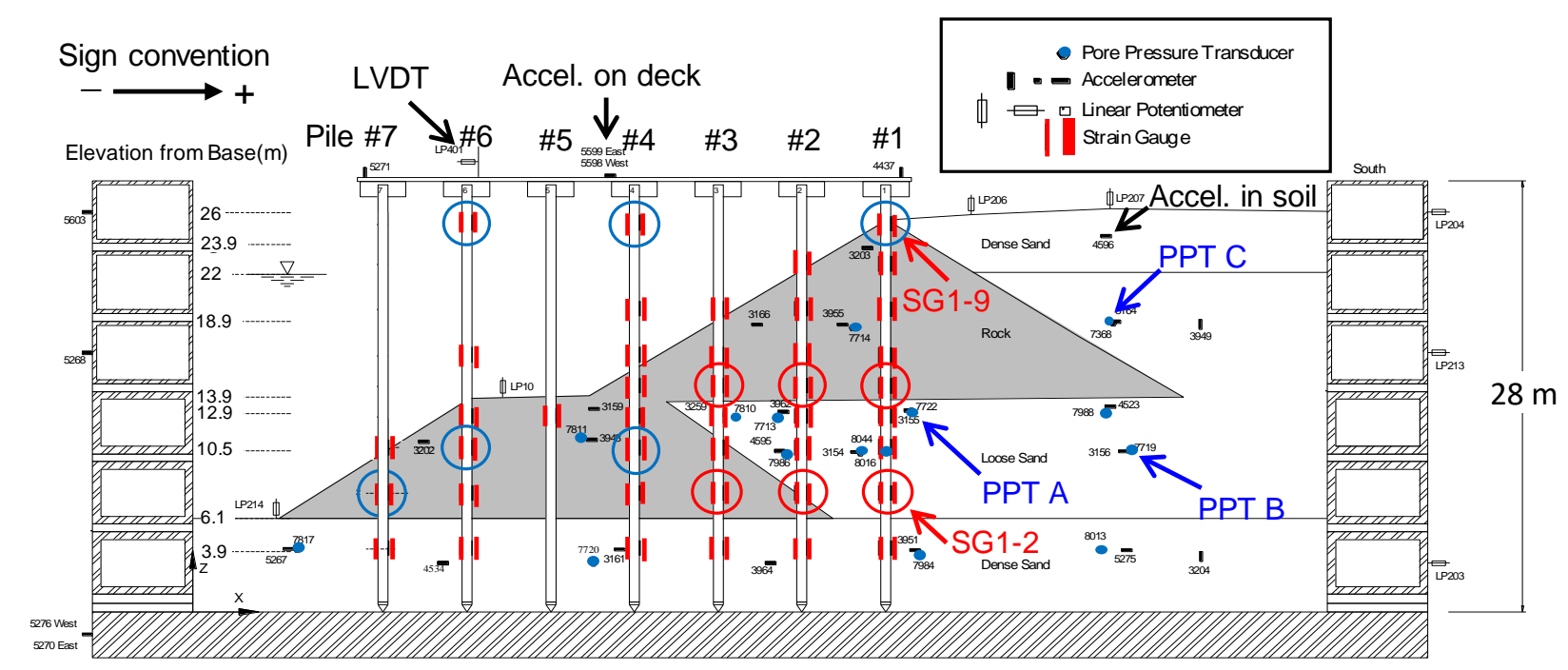

Figure 1. Cross section of pile-supported wharf centrifuge test NJM01 (prototype scale)

\section{MEASUREMENTS AND DATA PROCESSING}

The instrumentation data used in this analysis included accelerometers (mounted on the wharf deck, centrifuge box, and within the soil), Linear Variable Differential Transformers (LVDT; mounted on the wharf deck and centrifuge box in the horizontal direction and to the ground surface in the vertical direction), strain gauges (SG; mounted on the piles at various depths), and porewater-pressure transducers (PPT; located within the soil at various depths). This centrifuge test did not include a horizontal LVDT at the ground surface; therefore, the horizontal soil displacement profiles were calculated by double-integrating accelerations within and near the ground surface. The pile bending moments were calculated from strain gauge measurements. To calculate the lateral soil reaction (p), the bending moments were approximated using the Smooth Cubic Spline method and were double differentiated as described in Brandenberg et al. (2010). The bending moments and shear forces at pile tips were assumed to be zero.

\section{OBSERVATIONS BASED ON INSTRUMENTATION ARRAY}

The time histories of soil and pile responses, and input motions are shown in Figure 2 for the first main event in the NJM01 testing sequence, i.e., Oakland Outer Harbor Wharf motion scaled to 
PGA of $0.15 \mathrm{~g}$. The figure shows soil and pile displacements, wharf accelerations, excess porewater-pressures at three key locations in the model, bending moments at two critical locations along Pile \#1 (the rightmost pile on the cross section), and the soil reaction on Pile \#1 from the laterally spreading rockfill (13.2 $\mathrm{m}$ from pile head).

Displacements and Accelerations. The wharf deck displacement was measured using an LVDT that captured both transient and permanent displacements. Maximum wharf deck displacement was measured $0.17 \mathrm{~m}$ downslope. As previously described, the ground surface displacement at the upper dike was calculated by double integrating accelerations because this test did not include a horizontal LVDT at the ground surface. Therefore, the ground surface displacement measured here includes the transient component only. It is observed that the transient component of soil displacement is rather large in both directions with maximum downslope displacement being equal to $0.07 \mathrm{~m}$. These relatively large transient soil displacements are attributed to the inertia of the crust over the liquefied layer and contribute significantly to the bending moments at deeper elevations in the piles, as will be described later. To be consistent with the soil displacements, the wharf deck displacement was also calculated by double integrating accelerations at wharf deck to include the transient component only (black dashed-line in Figure 2 with maximum downslope displacement of $0.11 \mathrm{~m}$ ). The wharf accelerations are plotted as an indicative of the inertial force.

Pore-Water-Pressure. The excess pore-water-pressures ratios $\left(r_{u}\right)$ are shown for three locations within the loose sand layer showing partial liquefaction (Point $B, r_{u}=75 \%$ ) to full liquefaction (Point $\mathrm{A}, \mathrm{r}_{\mathrm{u}}=100 \%$ ). The $\mathrm{r}_{\mathrm{u}}$ values were later used in the $\mathrm{p}-\mathrm{y}$ analysis to estimate $\mathrm{p}$-multipliers.

Pile Bending Moments. The data from two strain gauges on Pile \#1 are plotted in Figure 2: SG19 at ground surface and SG1-2 at the bottom of the liquefied zone. SG1-2 experienced the maximum bending moment of all instrumented piles in the test. The deeper strain gauge (SG1-2) exhibited a combination of transient and permanent (end-of-shaking) components, while the response of the shallower strain gauge (SG1-9) was governed by a transient component with very small permanent component. We attributed the transient component of the bending moment in the deep strain gauge (SG1-2) to the transient component of soil displacements. It will be shown later that the bending moment at this strain gauge location can be reasonably estimated by considering soil displacements only (kinematics). The bending moment in the shallow strain gauge (SG1-9) can be reasonably estimated by combining kinematics with inertia.

Lateral Soil Reaction. The lateral soil reaction within the rockfill was back-calculated by doubleintegrating bending moments (Figure 2). The magnitude of back-calculated soil reaction was found sensitive to the method of approximating (or interpolating) bending moments and the noise in recorded data. Therefore, the soil reactions were primarily used to understand the direction of loading from soil on the piles. It was found that the soil reactions within the top nonliquefiable layer (rockfill) was not uniformly downslope. Instead, the soil reaction was maximum at the 
interface of rockfill and loose liquefiable sand, and reduced in the top half of the rockfill indicating that full passive crust load was not mobilized. The soil reaction at the bottom of rockfill $(13.2 \mathrm{~m}$ from pile head) was used as an indicative of the lateral spreading force (LSF).

Time of Peak Values. It is observed that the displacements, bending moments, and soil reactions in Figure 2 maximize during the strong shaking, and not necessarily at the end of shaking. For example, the residual wharf deck displacement (end-of-shaking) is $58 \%$ of its peak value during shaking ( $0.10 \mathrm{~m}$ compared to $0.17 \mathrm{~m}$ ). Similarly, the residual bending moment at depth (SG1-2) is $62 \%$ of its maximum value ( $474 \mathrm{kN}-\mathrm{m}$ compared to $768 \mathrm{kN}-\mathrm{m}$ ). The residual bending moment at the shallow strain gauge (SG1-9) is $9 \%$ of its peak value (38 kN-m compared to $437 \mathrm{kN}-\mathrm{m}$ ).

The maximum bending moments do not necessarily occur at the same time along the length of the pile. They also do not occur at the same time at the same elevation for various rows of piles. In order to compare the magnitude of moments at the same time, we identified a critical time (i.e., loading cycle) at which the soil and pile displacements, bending moments, and wharf accelerations are maximum, or close to maximum. The critical time $(t=21.6 \mathrm{sec})$ is marked with a vertical dashed line in Figure 2. At this time, the wharf acceleration is $0.13 \mathrm{~g}$, which is $90 \%$ of the peak wharf acceleration in the positive direction (resulting in downslope inertia) and $48 \%$ of the peak wharf acceleration in both directions. In the following section, we estimate pile bending moments recorded at $21.6 \mathrm{sec}$ by combining inertia and kinematics.

\section{CONTRIBUTION OF INERTIA AND KINEMATICS AT DIFFERENT DEPTHS}

Approach. The objective of this study was to identify inertial and kinematic loads on piles (i.e., bending moments) at different depths. To study this combination, key strain gauges were identified among all piles where bending moments were large at some point during the shaking. These strain gauges are circled in Figure 1. We used p-y models, calibrated to the results of the centrifuge test, to find the relative contribution of inertia and kinematics in bending moments at those key strain gauges. The p-y models were subjected to two loading conditions:

(a) Kinematic demands only (100\% Kinematics)

(b) Combined kinematic and inertial demands (100\% Kinematics + 100\% Inertia)

The kinematic demands were imposed by applying soil displacements to the end nodes of p-y springs. The soil displacements were calculated by double integrating accelerometers in soil. As described earlier, these soil displacements include the transient component only. The inertial demands can be applied as a shear load or an imposed displacement at pile head. While the total inertial load of the wharf deck can be calculated by multiplying total mass and the recorded acceleration, the relative distribution of the inertial load between seven rows of piles depends on the relative lateral stiffness of piles. This is difficult to do, because the lateral stiffness of the piles changes during shaking due to changes in soil properties. Therefore, it was decided to apply the inertial demand as an imposed displacement at pile head rather than a shear force. 

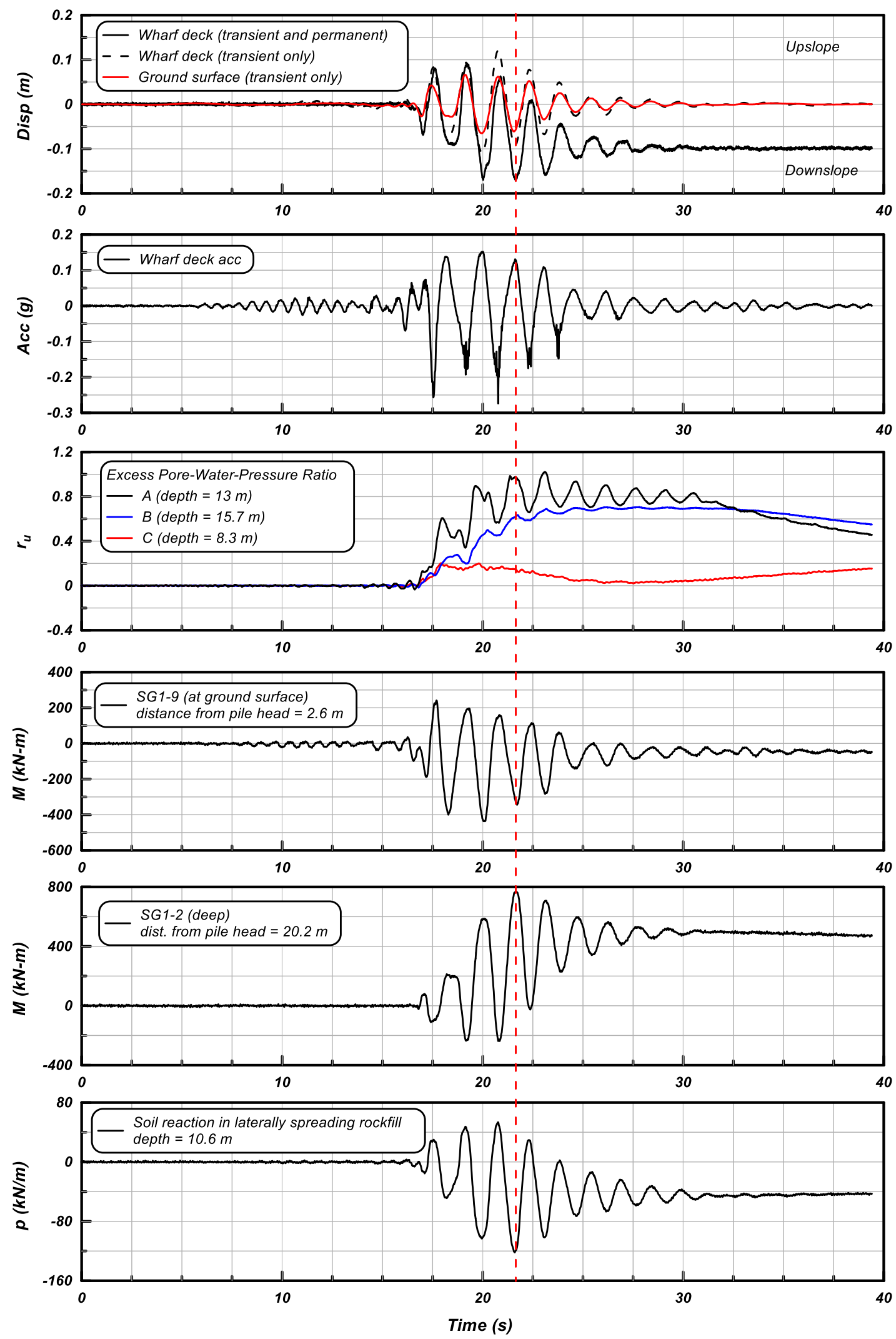

Figure 2. Representative time histories from the Loma Prieta Outer Harbor Wharf motion scaled to PGA of $0.15 \mathrm{~g}$ 
Assuming that the deck was relatively rigid during the test, the imposed pile head displacements were the same for all piles and were equal to the wharf displacement. To be consistent with the imposed soil displacements, only the transient component of the wharf displacement was applied (calculated by double integrating accelerations at wharf deck). The pile head was fixed against rotation to simulate the rigid pile-to-deck connection in the centrifuge test. The soil and pile displacements were extracted at $21.6 \mathrm{sec}$ which resulted in peak (or close to peak) bending moments.

The p-y model was created using LPILE (Ensoft 2014). The soil spring properties were calibrated based on a series of monotonic lateral load tests on piles in two other centrifuge tests conducted using similar soil and pile properties to those in the centrifuge test discussed in this paper. The Sand p-y curves in LPILE (Reese et al. 1974) were used with modifications based on the monotonic lateral load tests. The details of the calibration process and the recommended soil properties are provided in Dickenson and McCullough (2006). Two main adjustments were made to the soil springs: (i) the stiffness was reduced in sloping rockfill to account for the softer response observed in the centrifuge tests with monotonic loading, and (ii) p-multipliers were used in the liquefied zone based on recorded pore-water-pressure (PWP) following recommendations in Caltrans (2012), i.e. the p-multipliers for full liquefaction $\left(r_{u}=100 \%\right)$ were scaled by a factor of $100 / \mathrm{r}_{\mathrm{u}}$ for units where liquefaction did not fully trigger. The pile spacing was approx. 8 diameters; therefore, group reduction factors were not applied. Table 2 lists key properties used in p-y models.

Results. Figure 3a shows the snapshot of recorded bending moments at $21.6 \mathrm{sec}$ and the results of the p-y analyses for the two loading conditions described above, i.e. kinematics only (green lines) and kinematics plus inertia (blue lines). Figure $3 \mathrm{~b}$ shows the snapshot of soil displacements at 21.6 sec and pile displacements from the p-y analyses for the two loading conditions. It is observed that the effects of inertia attenuate within 5 to $6 \mathrm{~m}$ from the ground surface (approximately 8 to 10 pile diameters). The location of maximum (or large) recorded bending moments varied in different pile rows. In piles \#1, \#2 and \#3, large bending moments were recorded at pile head, and above and below the loose liquefiable layer. This was expected since the failure shear plane passed through the liquefied layer imposing significant curvature (and moment) in the piles. In piles \#4, \#6, and \#7, which did not pass through the loose liquefiable layer, large bending moments were recorded at pile head and at shallow depths (less than 10 diameters deep).

The location of strain gauges with large recorded bending moments are circled on Figure 1. Focusing on these strain gauges, it is observed that the magnitude of large bending moments above and below the liquefied zone (generally deeper than 10 diameters and marked with red circles in Figure 1) can be reasonably estimated by applying kinematic demands only in the p-y model. This indicates that these deep bending moments are primarily governed by soil displacements (100\% Kinematics). Conversely, the magnitude of large bending moments at pile head and shallow depths (marked with blue circles in Figure 1) can only be captured if both kinematics and inertia are applied in the p-y model. This indicates that inertia and kinematics fully interact at pile head and shallow depths, and that combined loads should be considered in design 
$(100 \%$ Kinematics $+100 \%$ Inertia). These results show that at depth of approximately 10 diameters we transition from "inertia + kinematics" to "kinematics only" in rockfill. It should be noted that this range may be valid only for the rockfill and the configuration of this test. Although the relative locations of the maximum bending moments were accurately predicted to form above and below the liquefied sand, the exact locations of the deeper maximum moments were inaccurately predicted and were approximately $2 \mathrm{~m}$ off ( 3 pile diameter). The uncertainty in predicting the location of maximum moments should be considered in design.

Table 2. Soil Properties Used in P-Y Models (LPILE)

\begin{tabular}{|l|l|l|l|c|}
\hline Material & P-Y Model & $\begin{array}{l}\text { Effective Unit } \\
\text { Weight } \\
\gamma^{\prime}\left(\mathrm{kN} / \mathrm{m}^{\wedge} 3\right)\end{array}$ & $\begin{array}{l}\text { Friction } \\
\text { Angle }(\mathrm{deg})\end{array}$ & $\begin{array}{l}\text { Subgrade } \\
\text { Reaction, } \mathrm{k} \\
(\mathrm{kN} / \mathrm{m} 3)\end{array}$ \\
\hline \hline Loose Nevada Sand $\left(\mathrm{D}_{\mathrm{R}}=39 \%\right)$ & Sand (Reese et al. 1974) & 9.6 & 33 & $5430^{1}$ \\
\hline Dense Nevada Sand $\left(\mathrm{D}_{\mathrm{R}}=82 \%\right)$ & Sand (Reese et al. 1974) & 10.6 & 37 & 33900 \\
\hline Rockfill & Sand (Reese et al. 1974) & 10.7 & 45 & $16300^{1}$ \\
\hline
\end{tabular}

1. Softened due to sloping ground

\section{DISCUSSION}

Pile demands (displacements, shear forces and bending moments) are shown in Figure 4 for Pile $\# 1$ at time=21.6 sec. The results of a sensitivity analysis with the $\mathrm{p}$-y model are also shown on this figure for comparison. The magnitude of bending moments above and below the liquefied layer (SG1-2 and SG1-5) is governed by kinematics (soil displacements) and are relatively unaffected by the inertia applied at top of the pile. To investigate the contribution of inertia at deeper locations, pile \#1 is analyzed by combining kinematics and different magnitudes of inertial demands. The inertial load at $21.6 \mathrm{sec}$ is estimated to range between $200 \mathrm{kN}$ (calculated by double integrating bending moments in the centrifuge test) and $320 \mathrm{kN}$ (by imposing wharf displacement of $0.09 \mathrm{~m}$ at pile head in the p-y model). Given this uncertainty, various magnitudes of inertial loads were applied at pile head in the sensitivity analysis (i.e., 0, 160, 320, and $480 \mathrm{kN}$ ). The objective of these analyses was to investigate how the inertial contribution dissipates with depth. It was found that the effects of pile head inertia are negligible at depths larger than 10 diameters below the ground surface. This depth corresponds to $\mathrm{z} / \mathrm{T}$ of approximately 4 if depth $(\mathrm{z})$ is normalized by the relative stiffness factor $(\mathrm{T})$ in rockfill (i.e., $\mathrm{T}=(\mathrm{EI} / \mathrm{k})^{(1 / 5)}$ where $\mathrm{EI}$ is the pile bending stiffness and $\mathrm{k}$ is the subgrade reaction).

The piles - having elastic stiffness representative of 24-in diameter steel pipe-piles or 24in square/octagonal prestressed concrete piles - are relatively flexible and follow the soil displacements pattern with depth. Therefore, the bending moments, which are the product of curvature in pile, were heavily dependent on the soil displacement pattern. This behavior may be different than the behavior reported for stiffer foundations (e.g. large diameter drilled shafts used for bridge foundations) where laterally spreading crust moves around the pile to the extent that it can mobilize full passive earth pressure (Boulanger et al. 2007; Caltrans 2012). 


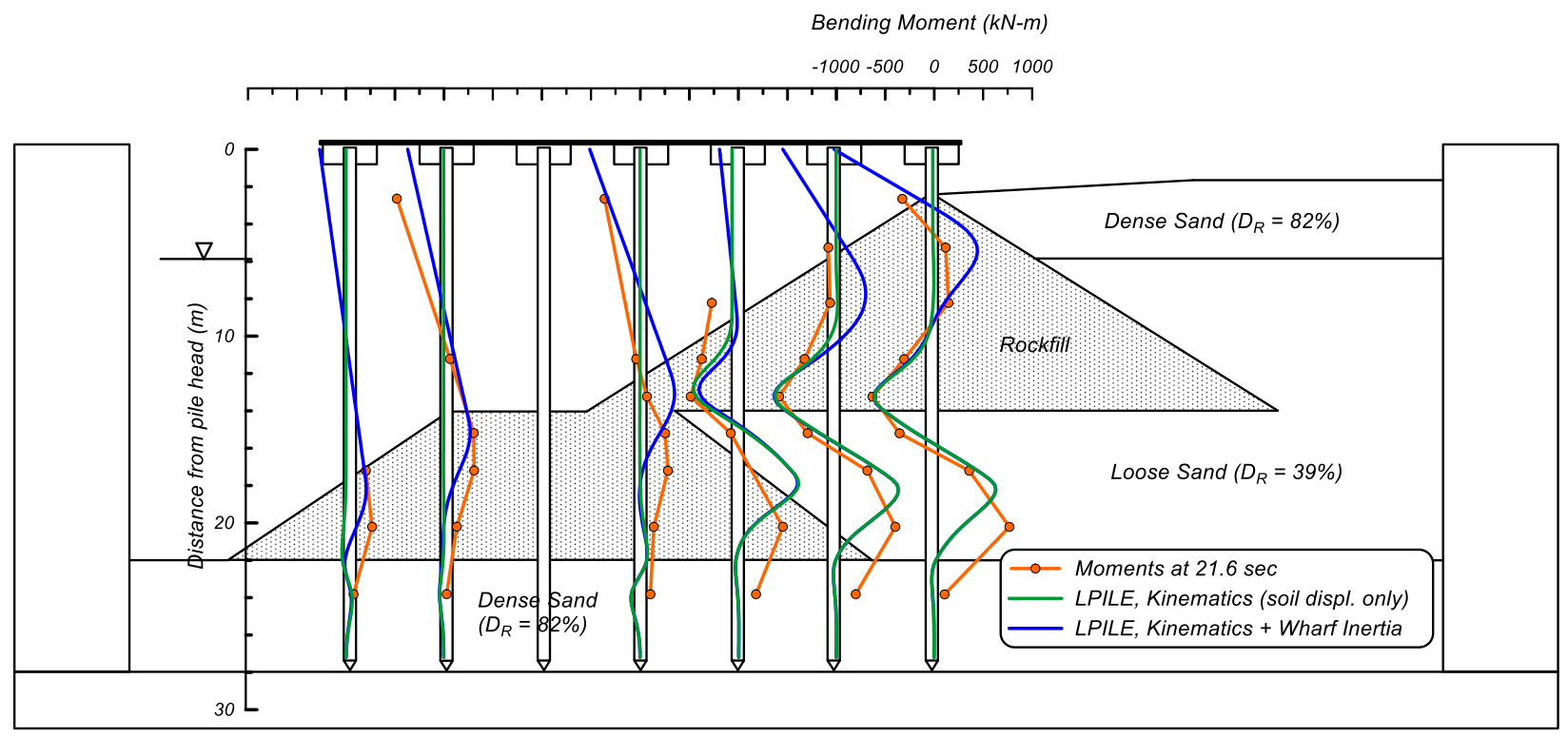

Figure 3a. Bending moments at the critical time $(21.6 \mathrm{sec})$ and moment profiles from p-y solutions (LPILE) - prototype scale

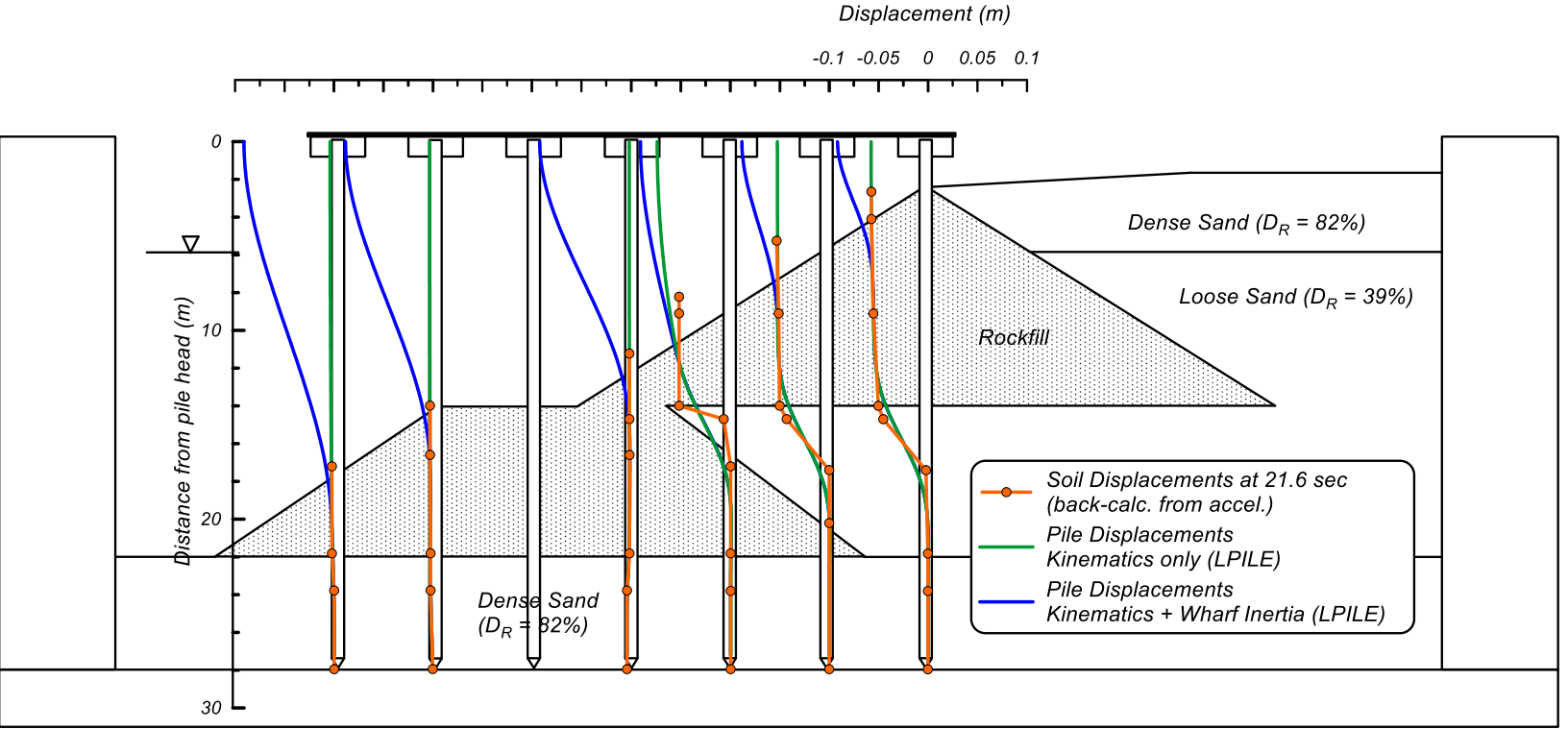

Figure 3b. Soil displacement profiles at the critical time $(21.6$ sec) calculated from accelerometers and pile displacements from p-y solutions (LPILE) - prototype scale

For the piles studied in this centrifuge test and the range of deformations observed, full passive pressure was not mobilized along the entire pile in the rockfill. Therefore, applying kinematic demands by imposing full passive pressure on piles will over-estimate pile demands. Applying kinematic demands by imposing soil displacements to the end nodes of p-y springs will estimate pile bending moments more accurately. Given the uncertainty in estimating the magnitude and pattern of soil displacements, sensitivity analysis is necessary to estimate the magnitude and location of kinematic demands. The uncertainties in the selection of soil spring properties should be considered in design as recommended in ASCE COPRI 61-14 by incorporating upper- and 
lower-bound spring stiffness for dynamic soil-structure-interaction (SSI) analysis. The soil displacement profiles in this study were calculated from acceleration recordings in the centrifuge test; however, the location of maximum bending moments were not estimated accurately. It is recommended that the uncertainties in the location of maximum bending moments be considered in design.

\section{CONCLUSIONS}

The physical modeling has provided a valuable data set for analysis of the time-, depth-, and rowdependent nature of kinematic and inertial loading on wharf piles in sloping rockfill. It was observed that pile bending moments were relatively large at soil interfaces with significant stiffness contrasts or at the shear failure plane. We found that $100 \%$ of kinematics (soil displacements) and $100 \%$ of inertia (wharf deck displacements) conservatively estimated bending moments at pile head and shallow depths (less than 10 diameters below the ground). On the contrary, applying $100 \%$ of kinematics was adequate to estimate pile bending moments at large depths (deeper than 10 diameters and above/below the liquefiable layer). These combination factors may be different for stiff shafts that are often used in bridge foundations and for significantly different soil profiles. For flexible piles, the flexibility of the foundation elements and the ability of the structure to move will have a significant impact on the pattern of kinematic loading on the structure. Therefore, uncertainties in the magnitude and patter of soil displacements with depth and soil spring properties should be considered in design as recommended in ASCE COPRI 61-14.
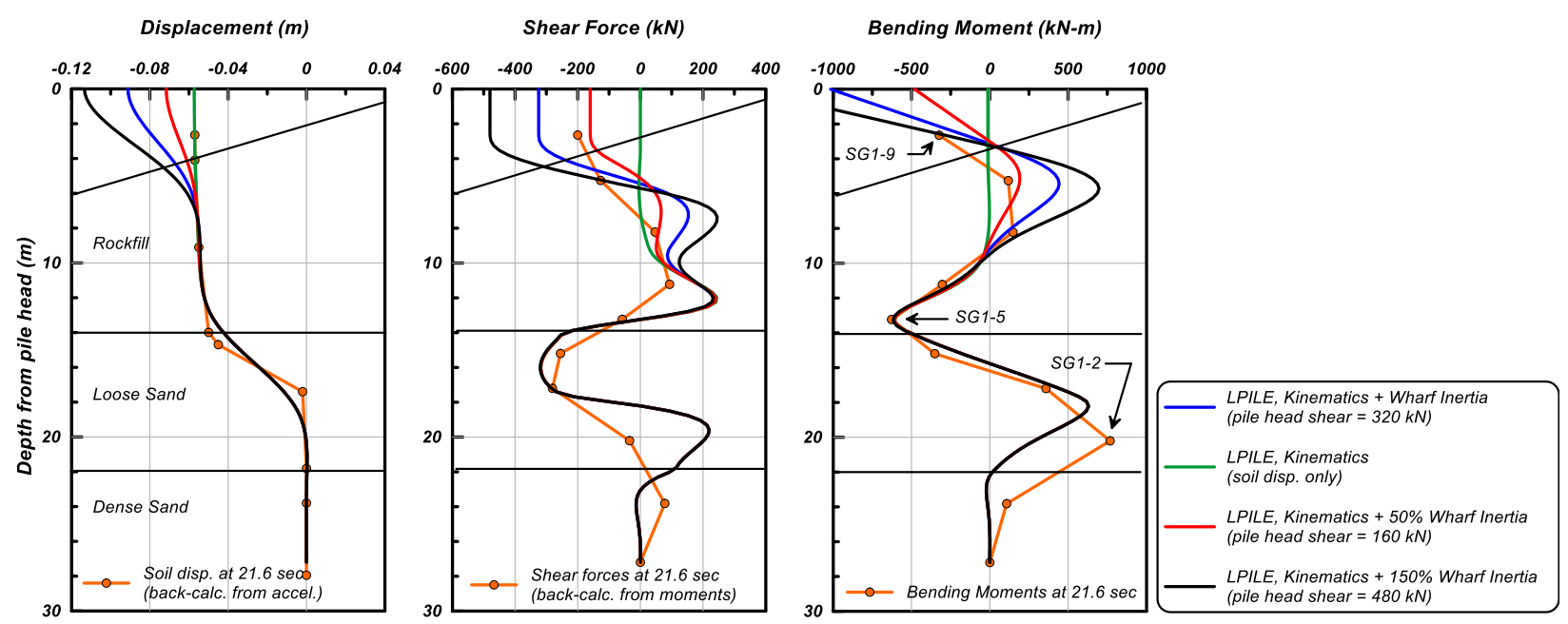

Figure 4. Comparison of displacement, shear force, and bending moment profiles recorded in and calculated from the centrifuge test and results of $p-y$ analyses combining full kinematic demands and varying contributions of wharf inertia 


\section{ACKNOWLEDGEMENTS}

The supports for centrifuge tests were provided by Grant No. CMS-9702744 from the National

Science Foundation and Grant No. SA2394JB from the Pacific Earthquake Engineering Research.

\section{REFERENCES}

AASHTO (2014). "Guide Specifications for LRFD Seismic Bridge Design.” Second Edition with 2014 Interim, AASHTO, Washington, D.C.

ASCE/COPRI 61-14 (2014). "Seismic Design of Piers and Wharves, prepared by the ASCE Standards Comm. on Seismic Design of Piers and Wharves." ASCE, Reston, VA.

Ashford, S.A., Scott, M.H., and Rayamajhi, D., (2012). "Reducing Seismic Risk to Highway Mobility: Assessment and Design Examples for Pile Foundations Affected by Lateral Spreading", ODOT

Brandenberg, S.J., Wilson, D.W., and Rashid, M.M. (2010). "A Weighted Residual Numerical Differentiation Algorithm Applied to Experimental Bending Moment Data.", J. Geo. and Geoenv. Engr., 136(6), 854-863

Boulanger, R.W., Chang, D., Brandenberg, S.J., Armstrong, R.J., and Kutter, B.L. (2007). "Seismic design of pile foundations for liquefaction effects." 4th International Conference on Earthquake Geotechnical Engineering, The Netherlands, 277-302.

California Department of Transportation (Caltrans) (2012). "Guidelines for Foundation Loading and Deformation Due to Liquefaction Induced Lateral Spreading." Sacramento, CA.

Dickenson, S.E., and McCullough, N.J. (2006). "Modeling the Seismic Performance of Pile Foundations for Port and Coastal Infrastructure," ASCE, Geo. Special Pub. No. 145, 173 - 191. Ensoft, (2014). "User's Technical Manual for LPile 2013"

McCullough, N.J., Dickenson, S.E., Kutter, B.L. and Wilson, D.W. (2000). "Pile-Supported Wharf - Centrifuge Model NJM01.” Report No. GEG01-2000, OSU-Geotechnical Engr.

McCullough, N. J., Dickenson, S. E., \& Schlechter, S. M. (2001). "The seismic performance of piles in waterfront applications." In Ports' 01: America's Ports: Gateway to the Global Economy (pp. 1-10).

Port of Long Beach (POLB) (2015). "Port of Long Beach Wharf Design Criteria," POLB WDC Version 4, May 2015.

Tokimatsu, K., Suzuki, H., Sato, M. (2005). "Effects of inertial and kinematic interaction on seismic behavior of pile with embedded foundation." Soil Dyn. EQ. Eng. 25, 753-762.

Reese, L. C.; Cox, W. R.; and Koop, F. D., 1974. "Analysis of Laterally Loaded Piles in Sand," Proceedings, 6th Offshore Technology Conference, Vol. II, pp. 473-484.

Washington Department of Transportation (WSDOT) (2015). "Geotechnical Design Manual.” M 46-03.11, May 2015. 